\title{
A tese da "nova clivagem" e a base social do apoio à direita radical
}

\author{
Pippa Norris \\ John F. Kennedy School of Government \\ Harvard University, Estados Unidos
}

\begin{abstract}
Resumo
A ascensão da direita radical está aberta a múltiplas interpretações. A questão abordada neste artigo é saber se muitos desses partidos criaram uma base social duradoura entre os eleitores e, se assim for, quais setores sociais apresentam maior probabilidade de apoiá.los. A primeira parte discute os marcos teóricos alternativos oferecidos pelos trabalhos clássicos dos anos 1950 e 1960, a tese da "nova clivagem social" comum durante a última década e a teoria do desalinhamento partidário. Em seguida, o artigo analisa hipóteses concorrentes sobre a base social do voto na direita radical em quinze países, usando dados retirados do Survey Social Europeu de 2002 e do Estudo Comparativo de Sistemas Eleitorais, 1996-2001. A segunda parte trata do papel de indicadores socioeconômicos, enquanto a terceira parte examina a duradoura diferença entre os sexos e os padrões geracionais de apoio. A conclusão considera as implicações desses resultados para compreender a base da popularidade da direita radical e para a estabilidade e longevidade desses partidos.
\end{abstract}

Palavras-chave: direita radical, voto, clivagem social, desalinhamento partidário, dados de surveys.

\begin{abstract}
The rise of the radical right is open to multiple interpretations. The question addressed in this paper is whether many of these parties have fostered an enduring social base among core voters and, if so, which social sectors are most likely to support them. The first part discusses the alternative theoretical frameworks provided by the classic accounts of the 1950s and 1960s, the "new social cleavage" thesis common during the last decade, and the theory of partisan dealignment. Then, it compares evidence to analyze rival hypotheses about the social basis of the radical right vote across fifteen nations, using data drawn from the European Social Survey, 2002, and the Comparative Study of Electoral Systems, 1996 . 2001. The second part focuses upon the role of socioeconomic indicators, while the third part considers the enduring gender gap and patterns of generational support. The conclusion considers the implications of these results for understanding the basis of radical right popularity, and for the stability and longevity of these parties.
\end{abstract}

Keywords: radical right, vote, social cleavage, partisan dealignment, survey data. 
O enigma central que este estudo busca explicar é por que os partidos de direita radical estabeleceram uma clara presença nos parlamentos nacionais em anos recentes numa grande diversidade de democracias, tais como Canadá, Noruega, França, Israel, Rússia, Romênia e Chile, e entraram em governos de coalizão na Suíça, Áustria, Holanda, Nova Zelândia e Itália, ao mesmo tempo que não conseguiram avanços comparáveis em sociedades similares, tais como Grã. Bretanha, Suécia e Portugal. A Figura 1 resume a popularidade crescente de alguns dos mais bem sucedidos partidos de direita radical na Europa ocidental. A ascensão destes partidos ocorreu tanto em sociedades predominantemente católicas como protestantes, em regiões nórdicas e mediterrâneas, na Noruega liberal e na conservadora Suíça, bem como na União Européia e nas democracias anglo. americanas. O enigma é maior porque eles cresceram em democracias estabelecidas, abastadas sociedades pós-industriais 'de conhecimento' e estados que garantem o bem estar social do berço à sepultura, com algumas das populações mais bem instruídas e seguras do mundo, características que deveriam gerar tolerância social e atitudes liberais opostas aos apelos xenofóbicos ${ }^{1}$. Além disso, os partidos de direita radical não estão confinados a esses países: eles também conquistaram apoio em certas nações pós-comunistas, bem como em algumas democracias latino-americanas.

\footnotetext{
1 Para a expectativa de que uma "revolução liberal" mundial desbancaria as atrações do autoritarismo, ver, por exemplo, o argumento apresentado por Fukuyama (1992).
} 
Figura 1

Participação média do voto em sete partidos de direita radical na Europa Ocidental, $1980-2004$

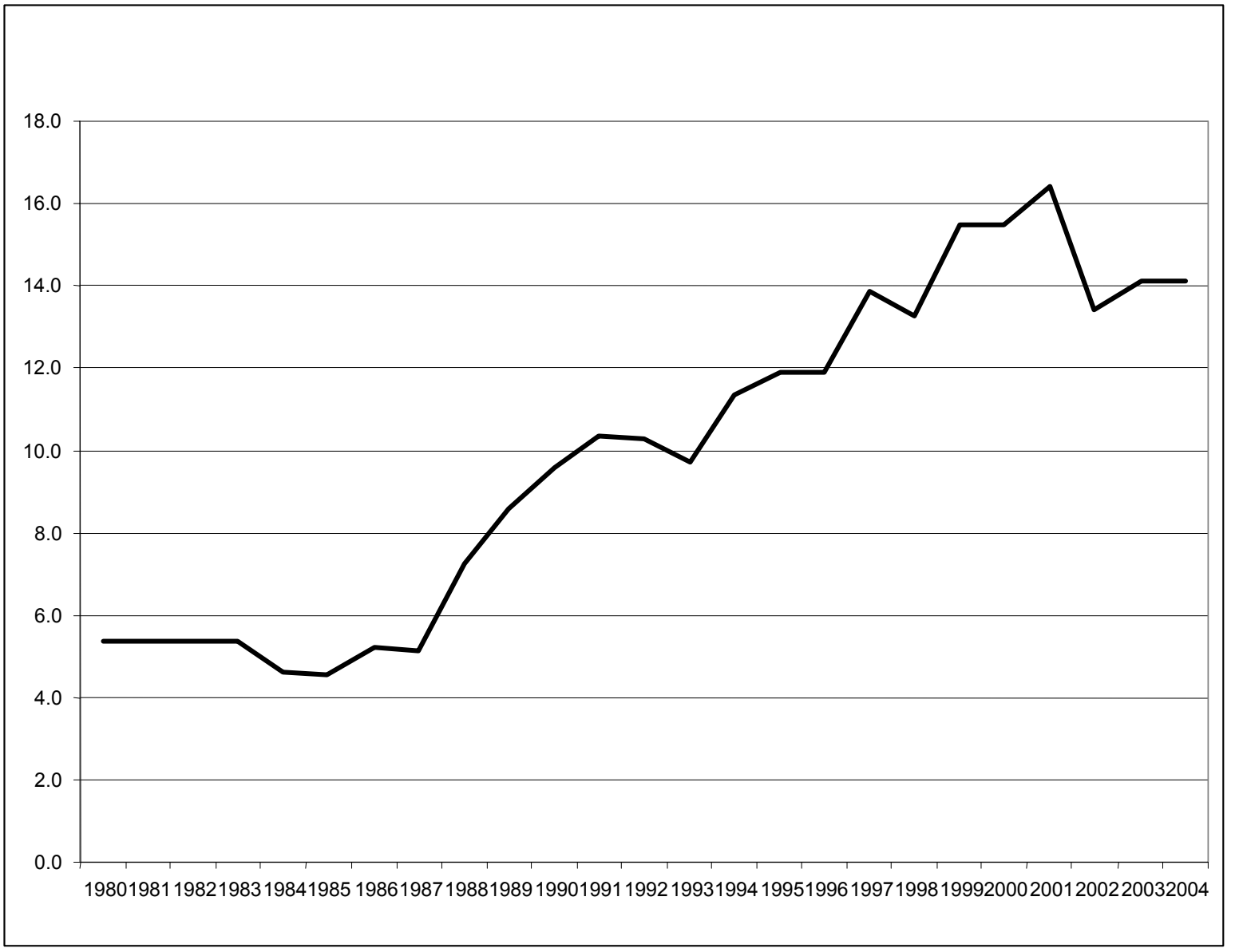

Nota: Esta figura resume a participação média do voto na câmara baixa de 1980-2004 para os seguintes partidos da Europa Ocidental, todos os quais participaram de uma série contínua de eleições parlamentares nacionais desde 1980: MSI/AN da Itália, FPÖ da Áustria, SVP da Suíça, FP/PP da Dinamarca, FrP da Noruega, VIB da Bélgica, FN da França. Todos esses partidos podem ser definidos como "relevantes", isto é, obtiveram mais de $3 \%$ do voto em uma ou mais eleições parlamentares nacionais durante o período. Nos casos italiano e dinamarquês, ocorreram divisões dentro dos partidos, mas ainda existem continuidades reconhecíveis nos partidos sucessores renomeados.

Fontes: MACKIE e ROSE, 1991 e 1997; dados sobre eleições recentes extraídos de Elections around the World, www.electionworld.org. 
A popularidade de figuras como Jean-Marie Le Pen, Jörg Haider e Pym Fortuyn provocou ampla preocupação popular e vasta literatura acadêmica ${ }^{2}$. Apesar do interesse, pouco consenso surgiu sobre as razões desse fenômeno. Este trabalho reexamina uma das questões clássicas sobre as condições sociais subjacentes que facilitam a ascensão da direita radical, proporcionando insights sobre a natureza da mudança eleitoral e as forças por trás dos padrões de competição partidária.

A primeira parte discute os marcos teóricos alternativos e examina as hipóteses concorrentes sobre a base social do apoio à direita radical em mais detalhes. O estudo compara então evidências para analisar a base social do voto na direita radical em quinze países, usando dados do Survey Social Europeu de 2002 e do Estudo Comparativo de Sistemas Eleitorais, 1996-2001. Estudos de caso anteriores que analisaram o apoio eleitoral a partidos específicos, tais como o Vlaams Blok ou a Lega Nord, apresentaram amiúde resultados inconsistentes. Essas variações podem ser atribuídas a contrastes genuínos encontrados em eleitorados nacionais, ou podem dever-se ao uso de classificações inconsistentes da estratificação social e classe ocupacional empregadas em estudos alternativos, bem como aos problemas comuns do tamanho limitado de amostras e erros de mensuração ${ }^{3}$. O número de respondentes incluídos nas amostras de vários países reunidas nos surveys usados neste estudo, combinado com a consistência das medidas e a amplitude dos indicadores que elas controlam em diferentes nações, nos permitem superar alguns desses problemas. A segunda parte trata do papel da estratificação social e a terceira examina a duradoura diferença entre os sexos e os padrões geracionais de apoio. A conclusão considera as implicações desses resultados para compreender a base da popularidade da direita radical e para a estabilidade e longevidade desses partidos.

Teorias estruturais da ascensão da direita radical

Dentre as múltiplas explicações oferecidas para a ascensão da direita radical na vasta literatura sobre o tema, as teorias estruturais, muito comuns em Sociologia, Psicologia Social e Economia Política, enfatizam as condições genéricas "de baixo para cima" de longo prazo - em especial, o crescimento de uma underclass marginalizada nas economias pós-industriais, padrões de fluxos

\footnotetext{
2 Para estudos comparativos ver, por exemplo, Hainsworth (1992, 2000); Merkl e Weinberg (1993, 1997); Betz (1994); Kitschelt (1995); Cheles, Ferguson e Vaughan (1995); Betz e Immerfall (1998); Gibson (2002); Schain, Zolberg e Hossay (2002); Ignazi (2003).

3 Por exemplo, Betz reúne muitos estudos separados da literatura, mas cada um deles usa medidas e definições de classe ocupacional e instrução levemente diferentes. Ver Betz (1994), Capítulo 5.
} 
migratórios e a expansão do desemprego de longo prazo - que teriam facilitado a ascensão dos partidos de direita radical como uma válvula de escape para as frustrações políticas dos perdedores nas sociedades abastadas ${ }^{4}$. As condições sociais são consideradas "estruturais" no sentido em que são compreendidas como fatores persistentes e duradouros que afetam o comportamento de todos os atores do sistema político. Essa relação envolve alguma endogenia; no longo prazo, as políticas públicas podem transformar gradualmente a sociedade, por meio, por exemplo, de cortes no bem estar social, aumentando o número de famílias que vivem na pobreza, ou de restrições legais ao influxo de imigrantes, de pessoas em busca de asilo e de refugiados. Não obstante, as teorias estruturais tratam a sociedade como o contexto "dado" dentro do qual os partidos políticos disputam qualquer eleição determinada.

Os partidos eleitorais menores e marginais continuam a ser, com freqüência, organizações frágeis e instáveis, vulneráveis a choques inesperados causados por divisões internas, difíceis transições de liderança, rivalidades entre facções ou súbitos escândalos. A história da direita radical está cheia de partidos de vida curta, exemplificados pelo movimento poujadista na França, o Partido Reformista nos Estados Unidos e o Lijst Pym Fortuyn na Holanda. Tais partidos podem crescer nas manchetes, numa onda de protestos públicos, para a consternação de muitos comentadores, ganhando assentos em eleições "atípicas", mas podem também voltar à obscuridade, quando as circunstâncias mudam. Sem lastro, eles oscilam na esteira da popularidade do governo e da oposição. Ao contrário, partidos menores que criaram raízes mais duradouras na massa do eleitorado, consolidando o apoio de sua base social e do núcleo dos fiéis ao partido, podem revelar-se mais resistentes às súbitas flutuações da fortuna eleitoral. Muitas vezes, eles conquistam um sucesso numa eleição "crítica" e conseguem consolidar-se e crescer nas eleições subseqüentes com base nesse êxito. Nessas circunstâncias, certos partidos de direita radical se revelaram mais duráveis. A Alleanza Nationale, por exemplo, reestruturada em 1994 como Movimento Sociale Italiano (MSI), foi fundada em 1946. O Front National de Le Pen sobreviveu a turbulentos altos e baixos eleitorais numa longa série de eleições desde sua fundação, em 1972, com um avanço decisivo em 1984. O Freiheitliche Partei Österreichs (FPÖ) foi fundado como uma organização mais moderada em 1956, mas deslocou-se fortemente para a direita depois de 1986, sob a liderança de Jörg Haider. A questão é saber se muitos partidos de direita radical criaram uma base social duradoura e atraíram um núcleo de fiéis e, se esse for a caso, quais setores sociais apresentam maior probabilidade de apoiá-los.

\footnotetext{
${ }^{4}$ Essa perspectiva é exemplificada por Betz (1994).
} 
Desde os primeiros trabalhos sobre as origens do fascismo e do autoritarismo, muitos estudos de Sociologia Política examinaram essas questões. Três abordagens distintas surgiram na literatura ${ }^{5}$. Os trabalhos clássicos publicados nos anos 1950 e 1960 procuravam explicar o fenômeno da ascensão do fascismo da Alemanha de Weimar, do poujadismo na França e do macartismo nos Estados Unidos como uma "revolta contra a modernidade", liderada principalmente pela pequena burguesia - pequenos empresários, pequenos comerciantes, artesãos e agricultores independentes - espremidos entre o poder crescente do big business e a influência coletiva dos trabalhadores organizados ${ }^{6}$. Teóricos contemporâneos, fazendo eco e atualizando essas preocupações, sustentam que "uma nova clivagem social" surgiu nas sociedades ricas. Desse ponto de vista, ainda podem ser detectados alguns elementos residuais da atração exercida pela direita radical sobre a pequena burguesia, mas na última década, sua retórica populista encontrou terreno mais fértil para crescer em uma underclass de trabalhadores com pouca especialização e segurança mínima no emprego e entre aquelas populações mais vulneráveis aos novos riscos sociais que afligem as sociedades ricas ${ }^{7}$. Numa outra visão, as teorias do desalinhamento partidário sugerem que hoje a atração da direita radical não se baseia em uma única clivagem social comum a todos os países, seja a classe trabalhadora não especializada ou a pequena burguesia. Em vez disso, a teoria prevê variações significativas na base social de apoio aos partidos da direita radical e uma erosão da relação entre estrutura social e lealdades partidárias sobre o comportamento dos eleitores.

Trabalhos sociológicos clássicos: uma crise da modernidade?

A obra clássica sobre comportamento eleitoral de Lipset e Rokkan enfatizava que as clivagens sociais modelavam padrões de competição partidária na Europa ocidental (LIPSET e ROKKAN, 1967). Eles afirmavam que os alicerces duradouros dos partidos políticos formavam-se a partir de divisões históricas no eleitorado, existentes na época da expansão do sufrágio universal, entre católicos e protestantes, regiões centrais e periféricas e patrões e trabalhadores. Acreditava-se que os partidos refletiam e canalizavam esses interesses para a esfera pública.

\footnotetext{
${ }^{5}$ Observe-se que as teorias da economia política baseadas em "desempenho" são diferentes dos estudos sociológicos que tratam de tendências seculares, pois os economistas políticos enfatizam o impacto de eventos mais específicos no desempenho das políticas governamentais sobre o apoio à direita radical, especialmente surtos de imigração, de refugiados e de pessoas em busca de asilo, combinado com taxas de desemprego e de insegurança no emprego nos setores mais pobres. Ver Givens (2002); Golder (2003).

${ }^{6}$ Exemplificada por Lipset (1960); Bell (2001).

7 Betz (1994), Capítulos 1 e 5; Ignazi (2003). Ver também Kitschelt (1995), Tabela 2.11; Anderson e Bjorkland (1990).
} 
Essas teorias estruturais da sociologia política estão enraizadas em processos mais amplos da modernização social, identificando múltiplas tendências seculares de longo prazo, associadas à ascensão das sociedades industriais e pós-industriais ${ }^{8}$. Entre os desenvolvimentos econômicos mais fundamentais que modelaram as sociedades européias no início do século XX estão a consolidação da indústria manufatureira de larga escala por meio da economia de escala gerada pela linha de montagem, a sindicalização da força de trabalho e o crescimento do número de empregados, profissionais e gerentes, no setor de serviços. Esses fatos estavam intimamente associados à expansão da educação secundária e superior, ao crescimento da afluência da classe média e ao aumento dos padrões de vida.

Os primeiros trabalhos seminais de Sociologia Política ligavam esse desenvolvimento econômico e social às raízes do apoio ao fascismo na Itália e na Alemanha e ao macartismo nos EUA. Essas idéias estavam presentes na série de ensaios de The New American Right, editada por Daniel Bell, publicada pela primeira vez em 1955, e em Political Man, publicado por Seymour Martin Lipset em 1959. Temendo a mobilidade para baixo e a perda de status social, argumentavam Lipset e Bell, os movimentos de direita radical se aproveitavam dos temores e inseguranças daqueles que perdiam com a industrialização:

"Os movimentos extremistas têm muito em comum. Eles atraem as pessoas descontentes e psicologicamente sem lar, os fracassados pessoais, os socialmente isolados, os economicamente inseguros, os pouco instruídos, pouco sofisticados e autoritários" (LIPSET, 1960, p. 175) $)^{9}$.

Para Lipset, eram os pequenos empresários, em especial aqueles sem instrução e os socialmente isolados em áreas rurais e pequenas cidades, que compunham o apoio tradicional ao fascismo, apanhados entre a ameaça das grandes empresas e da indústria manufatureira, de um lado, e a força coletiva dos trabalhadores organizados, de outro. A pequena burguesia consistia de pequenos empresários, lojistas, comerciantes urbanos, artesãos trabalhando por conta própria e agricultores familiares independentes. Esses grupos se diferenciam em muitos aspectos. O que tinham em comum é que arriscavam suas modestas reservas de capital e não contavam com a segurança que vinha com as carreiras profissional e gerencial em grandes organizações, ou dos laços coletivos de um

\footnotetext{
8 Para alguns dos clássicos essenciais dessa literatura, ver Lerner (1958); Rostow (1952, 1960); Bell (1999).

${ }^{9}$ Lipset (1960), Capítulos 4 e 5. Ver também Bell (2001); Sauer (1967).
} 
sindicato. O autônomo e aquele que trabalhava em negócios familiares estavam expostos às forças do mercado e eram vulneráveis a súbitas depressões econômicas, hiperinflação ou elevação de juros. Porém, Bell e Lipset enfatizavam que era a ameaça de perda de status pela pequena burguesia em sociedades industriais, mais do que puras ameaças econômicas, que deflagrava seu ressentimento contra o big business e o trabalho organizado, aumentando a atração por movimentos americanos que ofereciam soluções populistas simples, exemplificadas pelo coughlinismo nos anos 1930, o macartismo nos anos 1950 e a John Birch Society nos anos 1960, bem como o apoio de massa ao fascismo na Itália e na Alemanha. Pesquisas históricas posteriores sobre as origens dos movimentos fascistas europeus durante o entre-guerras deram mais sustentação a essas conclusões (LINZ, 1976; MÜHLBERGER, 1987). Se há alguma continuidade histórica nas bases sociais da política contemporânea, então a teoria prevê que o apoio eleitoral aos partidos de direita radical se concentrará com mais força na pequena burguesia.

Trabalhos sociológicos modernos: uma "nova clivagem social"?

As explicações sociológicas modernas repetem, mas também atualizam, algumas dessas preocupações. As idéias centrais e os apelos ideológicos que caracterizaram o populismo e o fascismo em décadas anteriores diferem muito dos movimentos direitistas de hoje e essas alterações podem atrair uma base social diferente. A plataforma tradicional do fascismo do entre-guerras defendia economias corporativistas e controladas pelo Estado, com forte autoridade governamental construída em torno de uma liderança política hierárquica, ao passo que a direita contemporânea defende o livre mercado, o governo mínimo e é contra o Estado (MUDDLE, 2000). A questão que mobiliza o apoio à direita radical hoje não é o medo das grandes empresas e dos trabalhadores organizados per se, mas antes a ameaça do "outro", impulsionada por padrões de imigração, por pessoas que buscam asilo e pelo multiculturalismo. A direita radical respondeu ao modo como as sociedades pós-industriais modernas foram transformadas no final do século XX por múltiplos desdobramentos sociais que transformaram as condições de vida, as oportunidades e os padrões de desigualdade socioeconômica nas sociedades industriais avançadas. Entre essas mudanças estão os processos de globalização, reduzindo as barreiras nacionais para o trabalho, comércio e mobilidade de capital; a reestruturação liberal dos mercados econômicos e o encolhimento do Estado de bem-estar, reduzindo a proteção social e o declínio das comunidades locais e das tradicionais organizações formais da classe operária, exemplificadas pelos sindicatos e as cooperativas de trabalhadores. As análises sociológicas contemporâneas enfatizam que esses processos beneficiaram em larga medida os grupos sociais com as habilidades educacionais e cognitivas, a 
mobilidade geográfica e a flexibilidade de carreira profissional que thes permitem aproveitar as novas oportunidades econômicas e sociais nas sociedades abastadas (IGNAZI, 2003).

Ao mesmo tempo, os comentadores afirmam que essas mudanças deixaram para trás uma "underclass" residual de trabalhadores com pouca habilitação que enfrenta um encolhimento das chances de vida, piores oportunidades de emprego em tempo integral e carreiras seguras e bem pagas no mercado de trabalho, benefícios estatais reduzidos e condições crescentes de desigualdade social ${ }^{10}$. Os pobres menos instruídos ficam presos ao trabalho casual, de pouca especialização e baixo salário, em geral com segurança mínima no emprego. Seria possível pensar que esses grupos naturalmente gravitariam na direção de partidos estabelecidos socialistas, social-democratas, trabalhistas e comunistas de centro-esquerda ou extrema-esquerda, os defensores tradicionais dos desvalidos sociais, ou partidos conservadores estabelecidos que defendem a segurança, a lei e a ordem e a identidade nacional. Mas, em vez disso, dizem os teóricos, os partidos tradicionais têm sido incapazes ou não estão dispostos a responder a uma "clientela deslocada" gerada pelo aumento da desigualdade social e da insegurança social entre os perdedores da modernidade, combinado com um crescente multiculturalismo. Essas condições estimularam a política do ressentimento contra imigrantes, alimentando a chama acesa pela retórica populista e atiçada pelos líderes de partidos extremistas.

A velha esquerda talvez não tenha respondido a essas preocupações, a desigualdade social pode ter piorado, enquanto esses partidos se tornaram cada vez mais "catch-all" na busca de apoio entre as classes médias em rápida expansão; e as forças da globalização e das pressões do mercado internacional constrangeram a autonomia de governos de centro-esquerda de aprovar medidas protecionistas ${ }^{11}$. Tradicionalmente, a esquerda preocupava-se com proteção contra o tipo de desvantagem social que limita seriamente a capacidade dos assalariados de extrair renda do mercado de trabalho, tais como acidentes industriais, desemprego, doenças, invalidez e velhice. A proteção contra esses riscos sociais tornou-se o objetivo essencial dos Estados de bem-estar em toda a Europa ocidental do pósguerra e em outros lugares, com políticas sociais desenvolvidas principalmente por partidos social-democratas em aliança com o movimento operário, bem como por partidos cristão-democratas. Onde os partidos de centro-esquerda tradicionais deixaram de reconhecer ou responder ao surgimento de populações que

\footnotetext{
10 Ver, por exemplo, Esping-Andersen (1990, 1999); Pierson (1998).

${ }^{11}$ Com efeito, a relativa falta de desalinhamento de classe na política partidária sueca foi indicada como uma razão para que a direita radical não tenha conseguido muito avanço neste país. Ver Rydgren (2002, 2003).
} 
experimentam novos riscos sociais e onde os padrões de compressão econômica significaram fortes reduções nos gastos com o estado de bem-estar social, novas clivagens sociais no eleitorado que poderiam ser exploradas por novos partidos empreendedores tornaram-se possíveis. Ao mesmo tempo, Betz sugere que a individualização e a fragmentação social desgastaram a participação maciça em organizações coletivas tradicionais, redes sociais e movimentos de massa que costumavam mobilizar as comunidades operárias, exemplificados pelas cooperativas de trabalhadores e o movimento sindicalista. Os partidos socialistas e sociais-democratas funcionavam no passado como um canal para a organização coletiva e a expressão das demandas das classes trabalhadoras.

Betz sugere que são esses novos grupos em desvantagem social os mais propensos a culpar as minorias étnicas pela deterioração das condições, a apoiar o protecionismo cultural e a criticar o governo por não oferecer a prosperidade e a segurança social que era característica da Europa do pós-guerra. Nessa visão, o fracasso das elites políticas de centro-esquerda em restaurar um sentimento de segurança e prosperidade para os desempregados e desprivilegiados na Europa ocidental alimenta o apoio a líderes populistas que fazem tais promessas (BETZ, 1994). Em suma, acredita-se que a política do ressentimento gera condições favoráveis aos líderes populistas que oferecem soluções simplistas. Há algumas provas empíricas que dão sustentação a esse argumento. Por exemplo, Lubbers, Gijsberts e Scheeepers mostraram que na Europa ocidental o apoio à direita radical no nível individual é significativamente mais forte entre os desempregados, operários, aposentados e setores menos educados, bem como entre os eleitores mais jovens, os não-religiosos e os homens ${ }^{12}$. No entanto, tratava-se de efeitos específicos e não difusos: eles não encontraram votação forte da direita em nações com desemprego mais alto ${ }^{13}$. A diferença de apoio aos partidos de extrema direita entre os sexos tem sido um padrão bem estabelecido e persistente, embora as razões disso não sejam bem compreendidas (GIVENS, 2004). Numa comparação entre cinco países, Niedermayer descobriu que os empregados de nível gerencial e os profissionais liberais estão consistentemente sub-representados nos eleitorados dos partidos de direita radical, embora também tenha demonstrado que a proporção de operários e de pessoas com baixo nível de instrução variava substancialmente entre diferentes partidos, como o FPÖ austríaco, os republicanos alemães e o Partido Progressista dinamarquês ${ }^{14}$.

\footnotetext{
12 Lipset (1960); Betz (1994); Lubbers, Gijsberts e Scheepers (2002), Tabela 4.

13 Lubbers, Gijsberts e Scheepers (2002). Ver também Lubbers e Scheepers (2001). Knigge também registrou uma relação negativa entre níveis nacionais de desemprego e apoio eleitoral aos partidos de extrema direita, Knigge (1998).

${ }^{14}$ Niedermayer (1990); Kitschelt (1995), Tabela 2.11.
} 
A análise em nível agregado, como a de Jackman e Volpert, também encontrou uma relação entre taxas de desemprego nacional e voto para partidos de extrema direita em cada país. Esses autores enfatizaram que se esperava que o efeito das condições macroeconômicas operassem em nível socio-trópico, afetando todos os grupos de uma sociedade, mas não necessariamente no nível ego-trópico, de modo que não se esperava que o apoio à direita radical fosse mais forte entre aqueles com experiência direta de desemprego de longo prazo, trabalhadores não qualificados ou setores sociais mais pobres. Uma ligação similar foi encontrada entre desemprego e voto na direita radical ao se analisar variações regionais na França e na Áustria (GIVENS, 2002). No entanto, Golder sustenta que há um efeito de interação, observando que o desemprego só importa onde a imigração é alta (JACKMAN e VOLPERT, 1996; GOLDER, 2003). A tese da nova clivagem, portanto, enfatiza que as tendências seculares "de baixo para cima" comuns em ricas sociedades pós-industriais, em particular o crescimento de populações em desvantagem sujeitas aos riscos sociais contemporâneos, criaram uma massa de cidadãos descontentes aberta aos acenos da direita radical. Se essa explicação for sustentada pelos resultados dos surveys reunidos por este estudo, analisados a seguir, devemos esperar encontrar que hoje o apoio eleitoral aos partidos sob comparação deve vir desproporcionalmente dos trabalhadores manuais não qualificados, dos menos instruídos e daqueles com experiência direta de desemprego ou insegurança no emprego.

Desalinhamento partidário e enfraquecimento dos perfis sociais

No entanto, nem todos os resultados são consistentes com essa tese. Por exemplo, Van der Brug, Fennema e Tillie examinaram o apoio a sete partidos de direita radical e constataram que eles atraíam igualmente apoio de todos os estratos sociais. Depois de controlar a proximidade ideológica e as atitudes políticas, eles descobriram que os indicadores de estratificação social raramente apresentavam uma associação significativa com o apoio partidário (inclusive o papel da classe social, renda, religião e instrução) e não encontraram padrões significativos consistentemente em todos os partidos (VAN DER BRUG, FENNEMA e TILLIE, 2000; VAN DER BRUG e FENNEMA, 2003). Estudos do comportamento eleitoral francês também sugerem que a classe ou o perfil religioso dos eleitores não são um preditor particularmente poderoso para explicar o apoio ao Front National (LEWIS-BECK e MITCHELL, 1993; VEUGELERS, 1997; MITRA, 1988). Os processos gerais de desalinhamento social e partidário podem ter corroído qualquer perfil social distintivo do eleitor da direita radical, junto com o papel das clivagens de classe e religião, na predição de apoio a muitos partidos tradicionais de centroesquerda e centro-direita. Um grande corpo de pesquisas sugere que a clivagem de classe na política partidária desapareceu aos poucos ao longo das últimas três 
décadas em muitas sociedades pós-industriais, com clivagens mais transversais surgindo nas sociedades multiculturais e um crescente desalinhamento partidário enfraquecendo as tradicionais lealdades eleitor-partido (CREWE, ALT e SARLVIK, 1977; NIE, VERBA e PETROCIK, 1976; CREWE e DENVER, 1985; FRANKLIN, MACKIE e VALEN, 1992; DALTON, FLANAGAN e BECK, 1984; FRANKLIN, 1985; MANZA e BROOKS, 1999; CLARK e LIPSET, 2001). A mais recente revisão dos dados feita por Dalton e Wattenberg comparou indicadores de ligações partidárias em uma ampla variedade de democracias industrializadas avançadas, com base na análise de pesquisas do Eurobarometer e de estudos de eleições nacionais. Eles concluíram que, ao longo do tempo, o número total do eleitorado que expressava uma identificação partidária diminuiu significativamente (no nível .10) em treze dos dezenove países comparados e o não-partidarismo disseminou-se mais entre os cidadãos mais instruídos e politicamente mais sofisticados, bem como entre a geração mais jovem (DALTON e WATTENBERG, 2001).

Se os traços de classe e das identidades partidárias não ancoram mais os eleitores nos partidos tradicionais em sucessivas eleições, isso pode ter conseqüências significativas para os padrões de volatilidade crescente no comportamento eleitoral e na competição partidária, abrindo a porta para mais votos divididos em diferentes níveis, para o surto súbito e ocasional de apoio a partidos baseados em política de protesto, bem como para mais troca de votos dentro e entre os blocos esquerda-direita de famílias de partidos (DALTON e WATTENBERG, 2001). A tese do desalinhamento sugere que a direita radical pode ser capaz de capitalizar os protestos políticos, beneficiando-se particularmente de qualquer descontentamento amplo e temporário com os partidos governantes, em eleições de segunda ordem realizadas durante os períodos dos mandatos principais, ou de eventos súbitos (como a onda de apoio ao Lijst Pym Fortuyn após o assassinato de seu líder), e captar votos geralmente de todos os setores, em vez de apresentar um perfil social distinto. Ao mesmo tempo, essa tese também sugere que qualquer ganho de curto prazo da direita radical pode se dissipar nas eleições subseqüentes, pois não está baseado em clivagens sociais e partidárias estáveis que façam os seguidores manterem-se fiéis aos partidos tanto nos bons como nos maus tempos. 
NORRIS, P. A tese da "nova clivagem" e a base social do apoio à direita radical

\section{Comparando a base socioeconômica de apoio}

Para recapitular as hipóteses alternativas centrais, as raízes da direita radical contemporânea continuarão a refletir os padrões de apoio eleitoral ao fascismo do entre-guerras na tese da "crise da modernidade" se for possível demonstrar que seus votos estão desproporcionalmente concentrados na pequena burguesia, seja de profissionais autônomos e gerentes, tais como agricultores familiares, arquitetos freelance e donos de restaurantes, ou de trabalhadores manuais por conta própria, tais como mestres de obras, taxistas e encanadores. Por outro lado, as análises sociológicas modernas do surgimento de uma "nova clivagem social" serão confirmadas se o apoio à direita radical em muitos países vier desproporcionalmente dos que estão em maior desvantagem social e dos setores mais pobres do eleitorado. E a tese do desalinhamento partidário será demonstrada se as clivagens sociais apresentarem apenas uma relação fraca com o comportamento eleitoral atual.

Que evidências podem ser usados para testar essas proposições? A análise dos surveys anteriores sobre a base social do voto na direita radical foi muitas vezes dificultada pela mensuração ruim da vulnerabilidade a novos riscos sociais, da experiência da insegurança de emprego e da desigualdade socioeconômica (inclusive medidas bastante toscas de categorias de classes sociais). Esse problema é agravado pelo tamanho limitado das amostras da maioria dos surveys sociais, restringindo a análise do pequeno número de eleitores da direita radical dentro de cada setor. Além disso, devido às limitações dos dados dos surveys e das medidas disponíveis, as análises anteriores deixaram amiúde de fazer a distinção com detalhes suficientes entre os diferentes segmentos da "nova" classe trabalhadora, tais como examinar quaisquer semelhanças no comportamento eleitoral dos profissionais autônomos e trabalhadores manuais por conta própria, bem como o apoio partidário daqueles com experiência direta de insegurança de emprego e financeira.

Para comparar vários países, este estudo se baseia no Survey Social Europeu (ESS) de 2002 e no Estudo Comparativo de Sistemas Eleitorais, 1996 2001 (CSES). Esses surveys facilitam comparações consistentes entre quinze nações industriais e pós-industriais que contêm partidos de direita relevantes, abrangendo diversos países anglo-americanos, europeus ocidentais e pós-comunistas, para ver se existem semelhanças no eleitorado tanto dentro como entre sociedades. Essas fontes também permitem análises de medidas mais finas da estrutura social e atitudinal de apoio à direita radical nos níveis individual, partidário e nacional. Tendo em vista a limitação de espaço, os detalhes completos desses surveys, o quadro comparativo e o conceito e definição de partidos de direita radical são apresentados em outro trabalho (NORRIS, 2005). 
O survey ESS-2002 inclui vários indicadores de privação social e experiência de desemprego de longo prazo. Usam-se coeficientes para apresentar os resultados, como maneira mais direta e clara de comparar o quanto o apoio dentro de cada grupo é maior ou menor do que a média do voto no partido entre todo o eleitorado de cada país. Os coeficientes são medidos como sendo a proporção de cada grupo que votou na direita radical dividida pela proporção do eleitorado nacional que votou na direita radical em cada país. Um coeficiente de 1.0 sugere que a proporção de um grupo que vota na direita radical reflete a quantidade de votos que o partido recebeu de todo o eleitorado (por exemplo, se a Lega Nord recebesse 10\% do voto nacional e o apoio de $10 \%$ da classe trabalhadora não-qualificada). Um coeficiente menor do que 1.0 indica que, em comparação com a média nacional, o grupo está sub-representado no voto na direita radical. E um coeficiente maior do que 1.0 (marcado em negrito nos quadros) sugere que, em comparação com a média nacional, o grupo está super-representado no voto nesses partidos.

Para testar o impacto da estratificação social com dados sistemáticos, seguimos a classificação de classes ocupacionais de Goldthorpe-Heath, usada por Heath, Jowell e Curtice para entender o eleitorado britânico, com base em um esquema criado originalmente pelo sociólogo John Goldthorpe (HEATH, JOWELL e CURTICE, 1985; GOLDTHORPE, 1980), que distingue cinco grupos: (1) os assalariados (empregados que são gerentes e administradores, supervisores e profissionais, com segurança, salários e status de carreira relativamente altos); (2) trabalhadores não-manuais de rotina (empregados como caixas de bancos, vendedores e secretárias, com mais baixa segurança no emprego, renda e prestígio); (3) a pequena burguesia (agricultores autônomos, pequenos proprietários e trabalhadores manuais por conta própria, expostos aos riscos do mercado por dependerem do capital próprio); (4) trabalhadores qualificados (eletricistas, maquinistas, artesãos); (5) operários não-qualificados (empregados mais temporários, como pedreiros, diaristas, domésticas, com as menores segurança no emprego, salário e status). Os respondentes foram classificados por seu trabalho, com base no código ocupacional ISC088, segundo seu pertencimento à população economicamente ativa, e não por sua condição de chefe de família. Tratamos neste estudo de modelos descritivos simples que medem os efeitos diretos das clivagens sociais no voto, deixando de lado, no momento, qualquer efeito indireto que possa ir das clivagens sociais ao apoio partidário através de atitudes políticas. 
Tabela 1

Estrutura social dos votos da direita radical, ESS-2002

\begin{tabular}{|c|c|c|c|}
\hline & \multicolumn{3}{|c|}{$\begin{array}{l}\text { Preditores de voto para a direita radical, } \\
\text { amostra reunida de } 8 \text { naçôes européias }\end{array}$} \\
\hline & $\mathrm{B}$ & Erro padrão & Sig. \\
\hline (Constante) & -3.08 & & \\
\hline \multicolumn{4}{|l|}{ DADOS DEMOGRÁFICOS } \\
\hline Idade (em anos) & .005 & .002 & ** \\
\hline Sexo $($ Masc. $=1$, Fem. $=0)$ & .307 & .074 & $* * *$ \\
\hline Minoria étnica (Minoria étnica $=1$, outros $=0$ ) & -1.04 & .249 & $* * *$ \\
\hline \multicolumn{4}{|l|}{ STATUS SOCIOECONÔMICO } \\
\hline $\begin{array}{l}\text { Instrução (nível mais alto atingido numa escala de } 6 \\
\text { pontos de baixa a alta) }\end{array}$ & -.051 & .030 & $\mathrm{~N} / \mathrm{s}$ \\
\hline Assalariados (empregados profissionais e gerenciais) & -.267 & .120 & * \\
\hline Pequena burguesia (autônomos) & .297 & .105 & ** \\
\hline Trabalhadores manuais qualificados & .372 & .119 & ** \\
\hline Trabalhadores manuais não-qualificados & .390 & .102 & $* * *$ \\
\hline Já esteve desempregado (por mais de 3 meses) & .198 & .085 & ** \\
\hline $\begin{array}{l}\text { Religiosidade (auto-identificado como religioso numa } \\
\text { escala de } 7 \text { pontos) }\end{array}$ & -.033 & .012 & ** \\
\hline Nagelkerke $\mathrm{R}^{2}$ & .025 & & \\
\hline Porcentagem predita corretamente & 93.1 & & \\
\hline
\end{tabular}

Notas: O modelo apresenta o resultado de um modelo de regressão logística binária (logit), incluindo os coeficientes beta (B) não-padronizados, os erros padrões e sua significância, na amostra reunida de oito nações européias ponderada por desenho e tamanho da população. Os países foram escolhidos dentre os presentes no ESS-2002, conforme tivessem um partido de direita radical relevante: Áustria, Bélgica, Suíça, Dinamarca, Israel, Itália, Holanda e Noruega. A França foi excluída da amostra reunida porque a classificação ocupacional padrão não foi medida no survey. A variável dependente é se o respondente votou em um partido de direita radical. Confirmou-se que todos os coeficientes estavam livres de erros de multicolinearidade. As amostras reunidas continham 13.768 respondentes no total, incluindo 932 eleitores da direita radical (6,8\%). A categoria de classe social 'trabalhadores não-manuais de rotina' foi abandonada como caso default (de comparação) neste modelo. Sig.001 $=^{* * *}$; Sig $.01={ }^{* *}$; Sig $.05={ }^{*}$. Fonte: Amostra reunida de 8 nações, Survey Social Europeu de 2002 (ESS-2002). 
A Tabela 1 apresenta o resultado de um modelo de regressão logística binária (logit), incluindo os coeficientes beta (B) não-padronizados, os erros padrões e sua significação, na amostra reunida de oito nações européias. Os países foram escolhidos dentre os presentes no ESS.2002 conforme tivessem um partido eleitoral de direita radical relevante, definido como aqueles com mais de $3 \%$ do voto: Áustria, Bélgica, Suíça, Dinamarca, Israel, Itália, Holanda e Noruega. A variável dependente é se o respondente votou em um partido de direita radical. Os resultados do modelo confirmam que quase todos os indicadores sociais básicos foram significantes no nível de probabilidade convencional de .95 e os coeficientes apontaram na direção prevista; a única exceção foi a instrução, negativamente relacionada ao apoio à direita radical, como predito, mas que só foi significante no nível de probabilidade .90 . Os resultados confirmam o que muitos outros encontraram em estudos anteriores, a saber, que nesses países, o apoio à direita radical era significativamente mais forte entre a velha geração e entre os homens, e que os eleitores de minorias étnicas estavam sub-representados. A análise por classe social indica que o apoio à direita radical estava sub-representado entre os assalariados e super-representado entre a pequena burguesia, bem como entre os trabalhadores manuais qualificados e não qualificados. Ademais, o apoio a esses partidos era maior entre aqueles que haviam experimentado o desemprego, bem como entre os menos religiosos. Esse perfil social dos eleitores da direita radical reflete, de modo geral, aquele encontrado antes por Lubbers, Gijsberts e Scheepers (2002), baseado numa análise de outros surveys em vários países da Europa ocidental em meados dos anos noventa, fortalecendo a confiança na estabilidade desses resultados ${ }^{15}$.

No conjunto, esses padrões sugerem que as características estruturais continuam diferenciando os eleitores da direita radical; sem dados de séries temporais consistentes, não podemos definir se o impacto dessas variáveis enfraqueceu ao longo dos anos, como as teorias do desalinhamento partidário afirmam. Porém, o que podemos concluir com mais certeza é que os partidos de direita radical não estão atraindo igualmente todos os setores sociais, por exemplo, baseados em protestos políticos temporários e em um período de amplo desencanto público com a política tradicional, como alguns estudos anteriores sugeriram (VAN DER BRUG, FENNEMA e TILLIE, 2000). A contínua atração da direita radical contemporânea exercida sobre a pequena burguesia, por exemplo, indica que há raízes mais profundas que também caracterizaram o fascismo do entre-guerras. Para ir adiante, os resultados reunidos precisam ser separados por

\footnotetext{
15 O estudo de Lubbers, Gijsberts e Scheepers (2002) usou dados derivados do Eurobarometer European Election Study de 1994 e do International Social Survey Program de 1998.
} 
nação e por tipo de clivagem social, bem como ser comparados com o perfil social do eleitorado de direita radical em outros países anglo-americanos e póscomunistas, para ver se há padrões consistentes nas sociedades pós-industriais.

Tabela 2

Base de classe dos eleitores da direita radical

\begin{tabular}{|c|c|c|c|c|c|c|c|}
\hline \multirow[t]{2}{*}{ País } & \multirow[t]{2}{*}{ Partido(s) } & \multirow{2}{*}{$\begin{array}{l}\% \text { que } \\
\text { votou na } \\
\text { direita } \\
\text { radical, } \\
\text { todos os } \\
\text { eleitores }\end{array}$} & \multicolumn{5}{|c|}{$\begin{array}{l}\text { Coeficiente de apoio eleitoral à direita radical em cada classe } \\
\text { comparada com a participação média nacional }\end{array}$} \\
\hline & & & Assalariado & $\begin{array}{l}\text { Não- } \\
\text { manual } \\
\text { de } \\
\text { rotina }\end{array}$ & $\begin{array}{l}\text { Pequena } \\
\text { burguesia }\end{array}$ & $\begin{array}{l}\text { Manual } \\
\text { qualificado }\end{array}$ & $\begin{array}{l}\text { Manual não } \\
\text { qualificado }\end{array}$ \\
\hline Áustria & FPÖ & 3.2 & 1.0 & 0.8 & 0.8 & 1.9 & 1.8 \\
\hline Bélgica & VB, FN & 4.4 & 0.5 & 0.9 & 1.3 & 2.3 & 1.4 \\
\hline Rep. Tcheca & RSC & 5.6 & 0.9 & 0.7 & 0.7 & 2.0 & 1.5 \\
\hline Dinamarca & $\mathrm{DF}, \mathrm{FP}$ & 6.8 & 0.3 & 0.9 & 0.9 & 1.4 & 1.6 \\
\hline França & $\mathrm{FN}$ & 3.2 & & & 0.8 & & \\
\hline Hungria & MIEP & 2.2 & 1.4 & 0.5 & 2.0 & 0.7 & 1.0 \\
\hline Israel & Mafdal, IL & 4.6 & 1.7 & 0.9 & 1.1 & 1.3 & 0.5 \\
\hline Itália & AN, LN, MsFt & 6.1 & 1.2 & 0.7 & 2.0 & 0.3 & 0.7 \\
\hline Holanda & $\mathrm{PF}, \mathrm{CD}$ & 11.5 & 0.6 & 1.2 & 1.1 & 1.1 & 1.1 \\
\hline Nova Zelândia & NZFP & 10.9 & 0.8 & 0.9 & 1.0 & 1.3 & 1.1 \\
\hline Noruega & FrP, FLP & 11.9 & 0.5 & 0.8 & 1.1 & 1.3 & 2.0 \\
\hline Romênia & PRM, PUNR & 3.2 & 0.3 & 1.3 & 2.4 & 1.3 & 0.9 \\
\hline Suíça & $\begin{array}{l}\text { SVP,EDU, SD, } \\
\text { LdT, FPS }\end{array}$ & 8.8 & 0.9 & 0.9 & 1.7 & 0.8 & 1.0 \\
\hline MÉDIA & & 6.2 & 0.8 & 0.9 & 1.3 & 1.3 & 1.2 \\
\hline
\end{tabular}

Notas: Os números representam o coeficiente de apoio de cada grupo à direita radical comparada com a média nacional (medida como a proporção de cada grupo que votou na direita radical dividida pela proporção do eleitorado nacional que votou na direita radical em cada país). Um coeficiente de 1.0 sugere que o grupo era perfeitamente proporcional à média nacional. Um coeficiente menor do que 1.0 sugere que o grupo estava sub-representado entre os eleitores da direita radical. Um coeficiente maior do que 1.0 (em negrito) sugere que o grupo estava super-representado entre os eleitores da direita radical.

Fontes: Áustria, Bélgica, Suíça, Dinamarca, França, Israel, Itália, Holanda e Noruega analisados a partir de dados do ESS-2002. Rep. Tcheca, Nova Zelândia, Romênia e Hungria foram analisadas a partir de dados do CSES 1996-2001. Observe-se que "autônomos" não foi classificada em Canadá, Rússia e Eslovênia, sendo necessário tirar essas nações da comparação nesta Tabela, enquanto a categoria ocupacional padrão não foi classificada na França. 
A Tabela 2 resume os coeficientes do voto de classe na direita radical em treze países com partidos de direita radical relevantes, sem qualquer controle prévio. As evidências confirmam que o apoio a esses partidos continua desproporcionalmente super-representado na pequena burguesia e nos trabalhadores manuais qualificados e não qualificados na maioria dessas nações. Em particular, comparado com o eleitorado geral, o apoio à direita radical é pelo menos duas vezes mais forte entre a pequena burguesia da Hungria, Itália e Romênia, mostrando a maior semelhança com as raízes clássicas do fascismo europeu. Em contraste, os assalariados estão sub-representados no eleitorado da direita radical em todos os países, exceto Hungria, Itália e Israel. Essa continua a ser a maior área de fraqueza eleitoral da direita radical, tendo em vista o tamanho limitado da pequena burguesia e o crescimento substancial dos empregados profissionais e gerenciais na economia do setor de serviços em expansão. Algumas diferenças importantes entre nações também ficam claras, exemplificadas pela base mais operária do FPÖ austríaco (confirmando o crescimento substancial de seu apoio entre a classe trabalhadora nas eleições da década de 1990, documentado em outro lugar $)^{16}$, em contraste com a maior atração que os romenos PRM e PUNR exercem sobre os eleitores de classe média inferior e a base mais forte da Lega Nord na pequena burguesia. Em outro lugar, examinamos se essas diferenças sociais relacionam-se com os padrões sistemáticos de apoio ideológico, pois as comparações de estudos de casos indicam que a base de classe diferente do FPÖ e da Lega Nord pode ser explicada pelos apelos programáticos divergentes, com a Lega Nord mantendo sua defesa de políticas neoliberais radicais de livre mercado, enquanto o FPÖ alterava sua plataforma sob a liderança de Haider para defender medidas mais protecionistas ${ }^{17}$.

\footnotetext{
16 Ignazi (2003), Tabela 6.2. Ver também Riedisperger (1992).

17 Betz (2002), pág. 76. Para detalhes, ver Norris (2005).
} 
NORRIS, P. A tese da "nova clivagem" e a base social do apoio à direita radical

Tabela 3

Grau de instrução dos eleitores da direita radical

\begin{tabular}{|c|c|c|c|c|c|}
\hline \multirow[t]{2}{*}{ País } & \multirow[t]{2}{*}{ Partido(s) } & \multirow{2}{*}{$\begin{array}{l}\text { \% que } \\
\text { votou na } \\
\text { direita } \\
\text { radical, } \\
\text { todos os } \\
\text { eleitores }\end{array}$} & \multicolumn{3}{|c|}{$\begin{array}{l}\text { Coeficiente de apoio eleitoral à direita radical } \\
\text { em cada classe comparada com a participação } \\
\text { média nacional }\end{array}$} \\
\hline & & & $\begin{array}{l}\text { Baixa } \\
\text { instrução }\end{array}$ & $\begin{array}{l}\text { Instrução } \\
\text { moderada }\end{array}$ & Alta instrução \\
\hline Áustria & FPÖ & 3.2 & 1.1 & 1.0 & 0.8 \\
\hline Bélgica & $\mathrm{VB}, \mathrm{FN}$ & 4.4 & 1.3 & 1.0 & 0.3 \\
\hline Canadá & $\mathrm{RP}$ & 18.9 & 0.9 & 1.1 & 0.9 \\
\hline Rep. Tcheca & RSC & 5.6 & 1.4 & 1.1 & 0.6 \\
\hline Dinamarca & $\mathrm{DF}, \mathrm{FP}$ & 6.8 & 1.4 & 1.1 & 0.1 \\
\hline França & $\mathrm{FN}$ & 3.2 & 1.5 & 0.5 & 0.5 \\
\hline Hungria & MIEP & 2.2 & 0.8 & 1.0 & 1.7 \\
\hline Israel & Mafdal, IL & 4.6 & 0.2 & 0.8 & 1.8 \\
\hline Itália & $\mathrm{AN}, \mathrm{LN}, \mathrm{MsFt}$ & 6.1 & 0.7 & 1.3 & 1.4 \\
\hline Holanda & $\mathrm{PF}, \mathrm{CD}$ & 11.5 & 1.1 & 1.0 & 0.7 \\
\hline Nova Zelândia & NZFP & 10.9 & 1.5 & 1.1 & 0.8 \\
\hline Noruega & FrP, FLP & 11.9 & 1.3 & 1.2 & 0.4 \\
\hline Romênia & PRM, PUNR & 3.2 & 0.6 & 1.2 & 1.3 \\
\hline Rússia & LDPR & 1.5 & 1.3 & 1.5 & 0.7 \\
\hline Eslovênia & SNS & 2.2 & 0.5 & 1.3 & 1.1 \\
\hline Suiça & $\begin{array}{l}\text { SVP, EDU, SD, LdT, } \\
\text { FPS }\end{array}$ & 8.8 & 0.7 & 1.2 & 0.5 \\
\hline MÉDIA & & 6.2 & 1.0 & 1.1 & 0.9 \\
\hline
\end{tabular}

Notas: Os números representam o coeficiente de apoio de cada grupo à direita radical comparada com a média nacional (medida como a proporção de cada grupo que votou na direita radical dividida pela proporção do eleitorado nacional que votou na direita radical em cada país). Um coeficiente de 1.0 sugere que o grupo era perfeitamente proporcional à média nacional. Um coeficiente menor do que 1.0 sugere que o grupo estava sub-representado entre os eleitores da direita radical. Um coeficiente maior do que 1.0 (em negrito) sugere que o grupo estava super-representado entre os eleitores da direita radical.

Fontes: Áustria, Bélgica, Suíça, Dinamarca, França, Israel, Itália, Holanda e Noruega analisados a partir de dados do ESS-2002. Canadá, Rep. Tcheca, Nova Zelândia, Romênia Rússia, Eslovênia e Hungria foram analisados a partir de dados do CSES 1996-2001.

O perfil educacional dos eleitores foi decomposto em maior detalhe na Tabela 3, que mostra um padrão similar entre os países, o que não surpreende, tendo em vista a ligação íntima entre grau de instrução anterior e status social subseqüente. De novo, a direita radical da Hungria (MIEP), Israel (Mafdal e IL) e Itália (AN, LN e MsFt) atraem desproporcionalmente os mais instruídos, assim como deixam uma marca mais forte entre os assalariados. Em quase todos os 
outros países, o apoio à direita radical tende a ser mais forte entre aqueles com instrução baixa ou moderada. Não obstante, há variações nesse padrão e seria exagero dizer que o apoio à direita está confinado aos que deixam a escola mais cedo, com nível mais baixo de instrução e sofisticação cognitiva.

Tabela 4

Indicadores sociais, tipo de área, e eleitores da direita radical

\begin{tabular}{|c|c|c|c|c|c|c|}
\hline \multirow[t]{2}{*}{ País } & \multirow[t]{2}{*}{ Partido(s) } & \multirow{2}{*}{$\begin{array}{l}\% \text { que votou } \\
\text { na direita } \\
\text { radical, todos } \\
\text { os eleitores }\end{array}$} & \multicolumn{4}{|c|}{$\begin{array}{l}\text { Coeficiente de apoio eleitoral à direita radical em } \\
\text { cada classe comparada com a participação média } \\
\text { nacional }\end{array}$} \\
\hline & & & $\begin{array}{l}\text { Desempregado } \\
\text { nos últimos } 5 \\
\text { anos }\end{array}$ & $\begin{array}{l}\text { Baixa } \\
\text { renda } \\
\text { familiar }\end{array}$ & $\begin{array}{l}\text { Vive em } \\
\text { área rural } \\
\text { ou cidade } \\
\text { pequena }\end{array}$ & $\begin{array}{l}\text { Vive em } \\
\text { cidade } \\
\text { grande }\end{array}$ \\
\hline Áustria & FPÖ & 3.2 & 0.8 & 0.8 & 1.2 & 0.6 \\
\hline Bélgica & $\mathrm{VB}, \mathrm{FN}$ & 4.4 & 1.6 & 1.1 & 1.2 & 0.9 \\
\hline Canadá & $\mathrm{RP}$ & 18.9 & 0.9 & 0.9 & 1.0 & 1.0 \\
\hline Rep. Tcheca & RSC & 5.6 & 2.3 & 1.1 & 1.2 & 0.1 \\
\hline Dinamarca & DF, FP & 6.8 & 1.1 & 1.2 & 0.9 & 0.8 \\
\hline França & FN & 3.2 & 0.8 & 0.9 & 0.8 & 0.6 \\
\hline Hungria & MIEP & 2.2 & 1.5 & 1.0 & 1.0 & 2.2 \\
\hline Israel & Mafdal, IL & 4.6 & 0.8 & 0.6 & 1.6 & 0.9 \\
\hline Itália & $\mathrm{AN}, \mathrm{LN}, \mathrm{MsFt}$ & 6.1 & 0.8 & 0.6 & 0.8 & 1.7 \\
\hline Holanda & $P F, C D$ & 11.5 & 1.4 & 0.9 & 1.0 & 0.9 \\
\hline Nova Zelândia & NZFP & 10.9 & 1.1 & 1.5 & 1.3 & 0.9 \\
\hline Noruega & FrP, FLP & 11.9 & 1.1 & 0.7 & 1.0 & 0.9 \\
\hline Romênia & PRM, PUNR & 3.2 & 0.3 & 0.8 & 1.0 & 1.0 \\
\hline Rússia & LDPR & 1.5 & 2.0 & 1.5 & 0.8 & 1.1 \\
\hline Eslovênia & SNS & 2.2 & 0.8 & 0.7 & 1.0 & 1.0 \\
\hline Suíça & $\begin{array}{l}\text { SVP, EDU, SD, } \\
\text { LdT, FPS }\end{array}$ & 8.8 & 0.6 & 0.9 & 1.1 & 0.2 \\
\hline MÉDIA & & 6.2 & 1.1 & 0.9 & 1.1 & 0.9 \\
\hline
\end{tabular}

Notas: Os números representam o coeficiente de apoio de cada grupo à direita radical comparado com a média nacional (medida como a proporção de cada grupo que votou na direita radical dividida pela proporção do eleitorado nacional que votou na direita radical em cada país). Um coeficiente de 1.0 sugere que o grupo era perfeitamente proporcional à média nacional. Um coeficiente menor do que 1.0 sugere que o grupo estava sub-representado entre os eleitores da direita radical. Um coeficiente maior do que 1.0 (em negrito) sugere que o grupo estava super-representado entre os eleitores da direita radical.

Fontes: Áustria, Bélgica, Suíça, Dinamarca, França, Israel, Itália, Holanda e Noruega analisados a partir de dados do ESS-2002. Canadá, Rep. Tcheca, Nova Zelândia, Romênia Rússia, Eslovênia e Hungria foram analisados a partir de dados do CSES 1996-2001. 
Podemos ir além desses indicadores básicos para ver também se aqueles com experiência de desemprego e os grupos mais pobres que vivem em famílias de baixa renda estão mais propensos a votar na direita radical, como muitos sugerem. Isso é importante, tendo em vista que muitos estudos de economia política em nível agregado sustentam que o aumento do desemprego, junto com a ameaça percebida dos trabalhadores imigrantes à segurança de emprego, desempenha um papel essencial na explicação da ascensão da direita radical na União Européia ${ }^{18}$. Podemos também examinar a localização dos respondentes, para ver se os votos nesses partidos concentram-se nos bairros urbanos pobres, ou se, como diziam os estudos clássicos do fascismo, nas áreas rurais e cidades pequenas. A Tabela 4 demonstra que as pessoas com experiência de desemprego estão superrepresentadas entre os eleitores da direita radical em cerca de metade dos países sob comparação, com efeitos particularmente fortes na República Tcheca e na Federação Russa. No entanto, dificilmente se pode dizer que os resultados oferecem uma confirmação forte às idéias de que a experiência individual de insegurança de emprego e desemprego é um fator importante do sucesso desses partidos. As comparações entre lares de baixa renda são ainda mais equívocas: o apoio à direita radical está super-representado nesse grupo apenas em um terço dos países comparados. A análise por área também demonstra que há padrões mistos, com seis países em que a direita radical era mais forte nas áreas rurais e somente três casos em que ela recebeu mais votos dos residentes urbanos. Em suma, a interpretação de que a direita contemporânea é simplesmente um produto do descontentamento dos setores mais pobres e menos instruídos parece ser um estereótipo exagerado; embora seja verdade que os partidos de direita radical da Áustria, Dinamarca e República Tcheca contem com considerável reservatório de apoio desses setores sociais, esses partidos também atraem consideráveis votos de todo o espectro na Hungria e na Holanda e ganham apoio levemente maior do que a média entre a pequena burguesia e os altamente instruídos na Itália e em Israel.

\section{Fatores demográficos: sexo e geração}

Pesquisas sobre diferenças entre os sexos no eleitorado têm sido um tema recorrente na ciência política desde os primeiros surveys sistemáticos do comportamento eleitoral (TINGSTEN, 1937, p. 37-65). Muitos esperavam - e outros temiam - que depois que as mulheres conquistaram o direito de votar, haveria um "voto feminino" distinto. O sexo não era considerado uma clivagem eleitoral

\footnotetext{
18 Ver, por exemplo, Jackman e Volpert (1996).
} 
importante, equivalente a classe, região e religião, porque mulheres e homens experimentavam muitas forças transversais, mas o estudo seminal sobre o comportamento eleitoral europeu de Lipset e Rokkan considerou o sexo como uma das clivagens secundárias que compunham a base eleitoral da política partidária (LIPSET e ROKKAN, 1967). Os primeiros clássicos dos anos 1950 e 1960 estabeleceram a ortodoxia na Ciência Política: as diferenças no voto entre os sexos eram, em geral, bastante modestas, mas as mulheres apresentavam maior probabilidade do que homens de apoiar partidos de centro-direita na Europa ocidental e nos Estados Unidos, padrão que foi chamado de "diferença tradicional entre os sexos" (DUVERGER, 1955, p. 65-6; LIPSET, 1960, p. 143; PULZER, 1967, p. 52; BUTLER e STOKES, 1974, p. 160; CAMPBELL et al., 1960, p. 493). A maioria das explicações desse fenômeno enfatizava as diferenças estruturais entre homens e mulheres em religiosidade, longevidade e participação na força de trabalho. Por exemplo, as mulheres italianas e francesas apresentavam maior probabilidade de freqüentar igrejas associadas a partidos democratas-cristãos (LIPSET, 1960, p. 260; BLONDEL, 1970, p. 55-56). Durante essa época, também costumava-se supor que as mulheres eram mais conservadoras em seus valores e atitudes políticos, produzindo uma diferença ideológica que estava na base de suas preferências partidárias $^{19}$. Contudo, ao mesmo tempo, muitos estudos indicavam que havia uma probabilidade muito maior de homens pertencerem a partidos de extrema direita, como o movimento fascista (LIPSET, 1960; GIVENS, 2004). A diferença tradicional entre os sexos na centro-direita desapareceu gradualmente e a literatura sugeriu que a velha tese do conservadorismo feminino não era mais evidente; em vez disso, a situação nos anos oitenta parecia depender das circunstâncias políticas: em algumas democracias estabelecidas, as mulheres pareciam se inclinar para a direita, em outras, para a esquerda, e em outras ainda, não era possível detectar nenhuma diferença significativa (LISTHAUG, MILLER e VALLEN, 1985; OSKARSON, 1995; MAYER e SMITH, 1985; DEVAUS e MCALLISTER, 1989; STUDLAR, MCALLISTER e HAYES, 1998; WILCOX, 1991; BANASZAK e PLUTZER, 1993a e 1993b; RUSCIANO, 1992). Porém, no final dos anos noventa, as mulheres haviam se deslocado para a centro-esquerda dos homens em muitas democracias estabelecidas (NORRIS e INGLEHART, 2003). Qual é o padrão na extrema direita? Houve mudanças semelhantes?

\footnotetext{
19 Porém, para um resumo crítico dos pressupostos da literatura inicial, ver Goot e Reid (1984).
} 


\section{Tabela 5}

Diferença entre os sexos entre os eleitores da direita radical

\begin{tabular}{|c|c|c|c|c|}
\hline \multirow[t]{2}{*}{ País } & \multirow[t]{2}{*}{ Partido(s) } & \multirow{2}{*}{$\begin{array}{l}\% \text { que } \\
\text { votou na } \\
\text { direita } \\
\text { radical, } \\
\text { todos os } \\
\text { eleitores }\end{array}$} & \multicolumn{2}{|c|}{$\begin{array}{l}\text { Coeficiente de apoio eleitoral à direita } \\
\text { radical em cada classe comparada com a } \\
\text { participação média nacional }\end{array}$} \\
\hline & & & Homens & Mulheres \\
\hline Áustria & FPÖ & 3.2 & 1.3 & 0.7 \\
\hline Bélgica & VB, FN & 4.4 & 1.2 & 0.8 \\
\hline Canadá & $\mathrm{RP}$ & 18.9 & 1.2 & 0.8 \\
\hline Rep. Tcheca & RSC & 5.6 & 1.4 & 0.6 \\
\hline Dinamarca & $D F, F P$ & 6.8 & 1.3 & 0.7 \\
\hline França & FN & 3.2 & 1.3 & 0.8 \\
\hline Hungria & MIEP & 2.2 & 1.2 & 0.9 \\
\hline Israel & Mafdal, IL & 4.6 & 1.0 & 1.0 \\
\hline Itália & $\mathrm{AN}, \mathrm{LN}, \mathrm{MsFt}$ & 6.1 & 1.4 & 0.7 \\
\hline Holanda & $\mathrm{PF}, \mathrm{CD}$ & 11.5 & 1.0 & 1.0 \\
\hline Nova Zelândia & NZFP & 10.9 & 1.0 & 1.0 \\
\hline Noruega & FrP, FLP & 11.9 & 1.2 & 0.7 \\
\hline Romênia & PRM, PUNR & 3.2 & 1.2 & 0.8 \\
\hline Rússia & LDPR & 1.5 & 1.6 & 0.7 \\
\hline Eslovênia & SNS & 2.2 & 1.0 & 1.0 \\
\hline Suíça & $\begin{array}{l}\text { SVP, EDU, SD, LdT, } \\
\text { FPS }\end{array}$ & 8.8 & 1.2 & 0.9 \\
\hline MÉDIA & & 6.2 & 1.2 & 0.8 \\
\hline
\end{tabular}

Notas: Os números representam o coeficiente de apoio de cada grupo à direita radical comparado com a média nacional (medida como a proporção de cada grupo que votou na direita radical dividida pela proporção do eleitorado nacional que votou na direita radical em cada país). Um coeficiente de 1.0 sugere que o grupo era perfeitamente proporcional à média nacional. Um coeficiente menor do que 1.0 sugere que o grupo estava sub-representado entre os eleitores da direita radical. Um coeficiente maior do que 1.0 (em negrito) sugere que o grupo estava super-representado entre os eleitores da direita radical.

Fontes: Áustria, Bélgica, Suíça, Dinamarca, França, Israel, Itália, Holanda e Noruega analisados a partir de dados do ESS-2002. Canadá, Rep. Tcheca, Nova Zelândia, Romênia Rússia, Eslovênia e Hungria foram analisados a partir de dados do CSES 1996-2001. 


\section{Tabela 6}

Perfil etário dos eleitores da direita radical

\begin{tabular}{|c|c|c|c|c|c|}
\hline \multirow[t]{2}{*}{ País } & \multirow[t]{2}{*}{ Partido(s) } & \multirow{2}{*}{$\begin{array}{c}\% \text { que } \\
\text { votou na } \\
\text { direita } \\
\text { radical, } \\
\text { todos os } \\
\text { eleitores } \\
\end{array}$} & \multicolumn{3}{|c|}{$\begin{array}{c}\text { Coeficiente de apoio eleitoral à direita radical } \\
\text { em cada classe comparada com a } \\
\text { participação média nacional }\end{array}$} \\
\hline & & & Mais jovem & Médio & Mais velho \\
\hline Austria & FPÖ & 3.2 & 0.9 & 0.8 & 1.8 \\
\hline Bélgica & VB, FN & 4.4 & 1.0 & 1.2 & 0.8 \\
\hline Canadá & $\mathrm{RP}$ & 18.9 & 0.8 & 1.1 & 1.1 \\
\hline Rep. Tcheca & RSC & 5.6 & 1.3 & 1.2 & 0.2 \\
\hline Dinamarca & DF, FP & 6.8 & 1.2 & 0.8 & 1.4 \\
\hline França & $\mathrm{FN}$ & 3.2 & 0.3 & 1.4 & 1.3 \\
\hline Hungria & MIEP & 2.2 & 0.7 & 1.1 & 1.1 \\
\hline Israel & Mafdal, IL & 4.6 & 0.9 & 1.2 & 0.9 \\
\hline Itália & $\mathrm{AN}, \mathrm{LN}, \mathrm{MsFt}$ & 6.1 & 0.7 & 1.1 & 1.0 \\
\hline Holanda & $\mathrm{PF}, \mathrm{CD}$ & 11.5 & 0.7 & 1.1 & 0.9 \\
\hline Nova Zelândia & NZFP & 10.9 & 0.7 & 1.0 & 1.6 \\
\hline Noruega & FrP, FLP & 11.9 & 0.9 & 1.0 & 1.1 \\
\hline Romênia & PRM, PUNR & 3.2 & 1.0 & 1.1 & 0.9 \\
\hline Rússia & LDPR & 1.5 & 1.2 & 1.1 & 0.7 \\
\hline Eslovênia & SNS & 2.2 & 1.7 & 0.6 & 0.3 \\
\hline Suíça & $\begin{array}{l}\text { SVP, EDU, SD, LdT, } \\
\text { FPS }\end{array}$ & 8.8 & 0.7 & 1.2 & 1.3 \\
\hline MÉDIA & & 6.2 & 1.0 & 1.0 & 1.0 \\
\hline
\end{tabular}

Notas: Os números representam o coeficiente de apoio de cada grupo à direita radical comparado com a média nacional (medida como a proporção de cada grupo que votou na direita radical dividida pela proporção do eleitorado nacional que votou na direita radical em cada país). Um coeficiente de 1.0 sugere que o grupo era perfeitamente proporcional à média nacional. Um coeficiente menor do que 1.0 sugere que o grupo estava sub-representado entre os eleitores da direita radical. Um coeficiente maior do que 1.0 (em negrito) sugere que o grupo estava super-representado entre os eleitores da direita radical.

Fontes: Áustria, Bélgica, Suíça, Dinamarca, França, Israel, Itália, Holanda e Noruega analisados a partir de dados do ESS-2002. Canadá, Rep. Tcheca, Nova Zelândia, Romênia Rússia, Eslovênia e Hungria foram analisados a partir de dados do CSES 1996-2001. 
Os resultados da comparação da Tabela 5 confirmam um padrão consistente: os homens continuam a ser super-representados no eleitorado da extrema direita em doze dos países e no outro não há diferença entre os sexos. A diferença no apoio entre os sexos é maior em relação aos democratas liberais da Rússia, o RSC na República Tcheca e na Itália. Embora alguns partidos, como o Front National de Le Pen, tenham feito um esforço especial para mudar sua imagem tradicional masculina, escolhendo algumas mulheres para concorrer a cargos, a liderança e a base desses partidos continuam predominantemente masculinas. Em outro trabalho, examino se esse padrão se deve às questões e políticas defendidas pela direita radical, tais como seus apelos xenofóbicos e contra o Estado, ou se pode ser atribuído, de um modo mais geral, a antigas diferenças entre os sexos quanto ao uso da violência e à associação dos movimentos de extrema direita com atos de agressão e táticas radicais de ação direta (NORRIS, 2005).

O perfil geracional é importante pois pode nos dizer muito sobre o futuro desses partidos. Se seu apoio é super-representado na velha geração, refletindo uma atração nostálgica do passado, então, no longo prazo, eles podem perder popularidade aos poucos, por meio do processo comum de substituição da população e encolhimento de sua base de massa. Se, porém, eles conseguem atrair e manter uma geração mais jovem, seduzindo fortemente, por exemplo, os jovens desempregados, então, isso poderá contribuir para sua expansão futura. A Tabela 6 demonstra o perfil etário dos eleitores da extrema direita. Os resultados mostram que há pouca consistência entre os países: em alguns (em especial a Rússia, a Eslovênia e a República Tcheca pós-comunistas), a geração mais jovem é desproporcionalmente atraída por esses partidos, mas em outros (Nova Zelândia, Suíça e Áustria, em particular), seu apelo é mais sentido pela geração mais velha. Isso sugere que o perfil específico desses partidos relacionado com a idade varia de país para país, o que pode se dever às suas raízes históricas em cada sociedade e à imagem de suas lideranças, estratégias de campanha e aos apelos ideológicos aos diferentes grupos de eleitores. 


\section{Conclusões}

Uma das maneiras clássicas de explicar os padrões de apoio partidário relaciona-se com a distribuição das clivagens sociais no eleitorado. Onde baseiamse em setores sociais distintos, os partidos podem forjar laços duradouros com esses grupos, representando seus interesses e preocupações no sistema político. Quando esses laços se enfraquecem, com desalinhamento social e partidário, então, devemos esperar maior volatilidade eleitoral e maior potencial para o voto de protesto. $\mathrm{O}$ que os resultados indicam sobre padrões duradouros de apoio à direita radical?

A comparação do perfil de classe social do eleitorado da extrema direita, incluindo indicadores de desigualdade social, sugere que eles estão desproporcionalmente super-representados na pequena burguesia, assim como nos trabalhadores qualificados e não-qualificados. Em muitos países, os padrões de apoio eleitoral no nível individual entre os desempregados e os residentes em domicílios de baixa renda não são tão fortes como sugerem muitos estudos de nível agregado da economia política. Essa coalizão entre classes significa que devemos ver com ceticismo a idéia de que a direita radical é somente um fenômeno do ressentimento político da "nova clivagem social" de trabalhadores pouco qualificados das grandes cidades, ou que sua ascensão pode ser atribuída de modo mecânico ao aumento do desemprego e de insegurança no emprego na Europa. 0 perfil social é mais complexo do que os estereótipos populares sugerem. Resta examinar se, como afirmam alguns, é a combinação particular de experiência do desemprego e atitudes contra os imigrantes que importa, em vez da insegurança apenas $^{20}$. Ao mesmo tempo, a diferença tradicional entre os sexos persiste, com os homens dando apoio a esses partidos. Ademais, embora a análise conjunta sugira que há alguns fatores comuns, os resultados desagregados por nação mostram variações consideráveis em quem vota na extrema direita. Em outro trabalho, examino com mais detalhes o impacto sistêmico de "eleições desalinhadas" e as conseqüências do enfraquecimento da lealdade eleitor-partido para os padrões da competição partidária e as oportunidades com que se defrontam os desafiantes da nova direita radical. Em alguns países, demonstro que o desalinhamento facilitou a ascensão desses partidos, com eleições "atípicas" ou "críticas", enquanto em outros casos, como Inglaterra e Estados Unidos, apesar de amplas evidências da erosão de longo prazo das identidades partidárias, os partidos de extrema direita não conseguiram superar as barreiras eleitorais para obter uma série sustentada de ganhos.

\footnotetext{
20 Tal como sustentado por Golder (2003).
} 
NORRIS, P. A tese da "nova clivagem" e a base social do apoio à direita radical

Portanto, com base nesses dados, podemos concluir que as teorias sociológicas clássicas de uma "crise da modernidade", ou os estudos modernos que enfatizam o surgimento de uma "nova clivagem social" não nos levam muito longe na explicação das variações de sucesso e fracasso dos partidos de direita radical. 0 que precisamos compreender não é apenas como as condições sociais podem facilitar sua ascensão mas, o que é mais importante, como os partidos reagem a esses fatores ao criar suas estratégias e apelos programáticos, ao montar sua organização e ao consolidar seu apoio.

\section{Referências Bibliográficas}

ANDERSON, J.G.; BJORKLAND, T. Structural changes and new cleavages: The Progress Parties in Denmark and Norway. Acta Sociologica, v. 33, n. 3, p. 195-217, 1990.

BANASZAK, L. A.; PLUTZER, E. The Social Bases of Feminism in the European Community. Public Opinion Quarterly, v. 57, n. 1, p. 29-53, 1993a.

. Contextual determinants of feminist attitudes: National and sub-national influences in

Western-Europe. American Political Science Review, v. 87, n. 1, p. 147-157, 1993b.

BELL, D. The Coming of Post-Industrial Society: A Venture in Social Forecasting. New York: Basic Books, 1999.

. (Ed.). The Radical Right. 3rd ed. New Brunswick, NJ: Transaction Publisher (publicado pela primeira vez em 1955 com o título The New America Right, posteriormente expandido na $2^{\mathrm{a}}$ edição de 1963), 2001.

BETZ, H.-G. Radical Rightwing Populism in Western Europe. New York: St Martin's Press, 1994.

The divergent paths of the FPÖ and the Lega Nord. In: SCHAIN, M.; ZOLBERG, A.;

HOSSAY, P. (Eds.). Shadows over Europe. New York: Palgrave, 2002.

BETZ, H.-G.; IMMERFALL, S. (Eds.). The New Politics of the Right: Neo-Populist Parties and Movements in Established Democracies. New York: St Martin's Press, 1998.

BLONDEL, J. Votes, Parties and Leaders. London: Penguin, 1970.

BUTLER, D.; STOKES, D. Political Change in Britain. 2nd ed. London: Macmillan, 1974. 
CAMPBELL, A. et al. The American Voter. Chicago: University of Chicago Press, 1960.

CHELES, L.; FERGUSON, R.; VAUGHAN, M. (Eds.). The Far Right in Western and Eastern Europe. New York: Longman, 1995.

CLARK, T. N.; LIPSET, S. M. (Eds.). The Breakdown of Class Politics. Baltimore, MD: The Johns Hopkins Press, 2001.

CREWE, I.; ALT, J.; SARLVIK, B. Partisan de-alignment in Britain 1964-1974. British Journal of Political Science, v. 7, n. 1, p. 129-90, 1977.

CREWE, I.; DENVER, D. (Eds.). Electoral Change in Western Democracies: Patterns and Sources of Electoral Volatility. New York: St. Martin's Press, 1985.

DALTON, R. J.; FLANAGAN, S.; BECK, P. A. (Eds.). Electoral Change in Advanced Industrial Democracies: Realignment or Dealignment? Princeton: Princeton University Press, 1984.

DALTON, R. J.; WATTENBERG, M. P. (Eds.). Parties without Partisans: Political Change in Advanced Industrial Democracies. New York: Oxford University Press, 2001.

DEVAUS, D. e MCALLISTER, I. The Changing Politics of Women: Gender and Political Alignments in 11 Nations. European Journal of Political Research, v. 17, n. 3, p. 241-262, 1989.

DUVERGER, M. The Political Role of Women. Paris: UNESCO, 1955.

ESPING-ANDERSEN, G. The Three Worlds of Welfare Capitalism. Princeton, NJ: Princeton University Press, 1990. 1999. . The Social Foundations of Post-industrial Economies. [New York]: Oxford University Press,

FRANKLIN, M. The Decline of Class Voting in Britain: Changes in the Basis of Electoral Choice, 1964-1983. Oxford: Clarendon Press, 1985.

FRANKLIN, M.; MACKIE, T.; VALEN, H. Electoral Change: Responses to Evolving Social and Attitudinal Structures in Western Countries. Cambridge: Cambridge University Press, 1992.

FUKUYAMA, F. The End of History and the Last Man. London: Hamish Hamilton, 1992. 
GIBSON, R. The Growth of Anti-Immigrant Parties in Western Europe. Lewiston, New York: The Edwin Mellen Press, 2002.

GIVENS, T. E. The role of socioeconomic variables in the success of radical right parties. In:

SCHAIN, M.; ZOLBERG, A.; HOSSAY, P. (Eds.). Shadows over Europe. New York: Palgrave, 2002.

The radical right gender gap. Comparative Political Studies, v. 37, n. 1, p. 30-54, 2004.

GOLDER, M. Explaining variations in the success of extreme right parties in Western Europe. Comparative Political Studies, v. 36, n. 4, p. 432-466, 2003.

GOLDTHORPE, J. H. Social Mobility and Class Structure in Modern Britain. Oxford: Clarendon Press, 1980.

GOOT, M.; REID, E. Women: If Not Apolitical, Then Conservative. In: SILTANEN, J.; STANWORTH, M. (Eds.). Women and the Public Sphere. London: Hutchinson, 1984.

HAINSWORTH, P. (Ed.). The Extreme Right in Europe and the USA. New York: St Martin's Press, 1992. Pinter, 2000.

(Ed.). The Politics of the Extreme Right: From the Margins to the Mainstream. London:

HEATH, A.; JOWELL, R.; CURTICE, J. How Britain Votes. Oxford: Pergamon, 1985.

IGNAZI, P. Extreme right parties in Western Europe. New York: Oxford University Press, 2003.

JACKMAN, R. W.; VOLPERT, K. Conditions favouring parties of the extreme right in Western Europe. British Journal of Political Science, v. 26, n. 4, p. 501-22, 1996.

KITSCHELT, H. The Radical Right in Western Europe: A Comparative Analysis. (com colaboração de Anthony J. McGann). Ann Arbor: University of Michigan, 1995.

KNIGGE, P. The ecological correlates of right-wing extremism in Western Europe. European Journal of Political Research, v. 34, n. 6, p. 249-79, 1998.

LERNER, D. The Passing of Traditional Society: Modernizing the Middle East. New York: Free Press, 1958. 
LEWIS-BECK, M.; MITCHELL, G. E. French electoral theory: The National Front test. Electoral Studies, v. 12, n. 2, p. 112-127, 1993.

LINZ, J. Some notes toward a comparative study of fascism in sociological historical perspective. In: LAQUER, W. (Ed.). Fascism: A Reader's Guide. Berkeley: University of California Press, 1976.

LIPSET, S. M. Political Man: The Social Basis of Politics. New York: Doubleday, 1960.

LIPSET, S. M.; ROKKAN, S. Party Systems and Voter Alignments. New York: Free Press, 1967.

LISTHAUG, O.; MILLER, A. H.; VALLEN, H. The Gender Gap in Norwegian Voting Behavior. Scandinavian Political Studies, v. 83, p. 187-206, 1985.

LUBBERS, M.; GIJSBERTS, M.; SCHEEPERS, P. Extreme right-wing voting in Western Europe. European Journal of Political Research, v. 41, n. 3, p. 345-378, 2002.

LUBBERS, M.; SCHEEPERS, P. Explaining the trend in extreme right-wing voting: Germany 19891998. European Sociological Review, v. 17, n. 4, p. 431-449, 2001.

MACKIE, T. T.; ROSE, R. The International Almanac of Electoral History. London: Macmillan, 1991.

A decade of election results: Updating the International Almanac. Studies in Public Policy, $\mathrm{n}$. 295. Strathclyde: CSPP, 1997.

MANZA, J.; BROOKS, C. Social Cleavages and Political Change: Voter Alignments and U.S. Party Coalitions. New York: Oxford University Press, 1999.

MAYER, L.; SMITH, R. E. Feminism and Religiosity: Female Electoral Behavior in Western Europe. In: BASHEVKIN, S. Women and Politics in Western Europe. London: Frank Cass, 1985.

MERKL, P. H.; WEINBERG, L. (Eds.). Encounters with the Contemporary Radical Right. Boulder: Westview, 1993.

1997.

(Eds.). The Revival of Right-Wing Extremism in the Nineties. London: Frank Cass,

MITRA, S. The National Front in France: A Single-Issue Movement?. West European Politics, v. 11, n. 2, p. 47-64, 1988.

MUDDLE, C. The Ideology of the Extreme Right. New York: St. Martin's Press, 2000. 
MÜHLBERGER, D. The Social Basis of European Fascist Movements. London: Croom Helm, 1987.

NIE, N.; VERBA, S.; PETROCIK, J. The Changing American Voter. Cambridge, MA: Harvard University Press, 1976.

NIEDERMAYER, O. Sozialstruktur, politische Orientierungen und die Uterstutzung extrem rechter Parteien in Westeuropa. Zeitschrift fur Parlamentsfragen, v. 21, n. 4, p. 564-82, 1990.

NORRIS, P. Radical Right: Parties and Electoral Competition. New York: Cambridge University Press (no prelo), 2005.

NORRIS, P.; INGLEHART, R. Rising Tide: Gender Equality and Cultural Change Worldwide. New York: Cambridge University Press, 2003.

OSKARSON, M. Gender Gaps in Nordic Voting Behavior. In: KARVONEN, L.; SELLE, P. (Eds.). Women in Nordic Politics. Aldershot: Dartmouth, 1995.

PIERSON, P. Irresistible forces, immovable objects: post-industrial welfare states confront permanent austerity. Journal of European Public Policy, v. 5, p. 539-60, 1998.

PULZER, P. G.J. Political Representation and Elections in Britain. London: George Allen \& Unwin, 1967.

RIEDISPERGER, M. Heil Haider! The revitalization of the Austrian Freedom Party since 1986. Politics and Society in Germany, Austria and Switzerland, v. 4, n. 3, p. 18-47, 1992.

ROSTOW, W. W. The Process of Economic Growth. New York: Norton, 1952.

. The Stages of Economic Growth. Cambridge: Cambridge University Press, 1960.

RUSCIANO, F. L. Rethinking the Gender Gap: The Case of West German Elections, 1949-87. Comparative Politics, v. 24, n. 3, p. 335-57, 1992.

RYDGREN, J. Radical right populism in Sweden: Still a failure, but for how long?. Scandinavian Political Studies, v. 25, n. 1, p. 27-56, 2002.

RYDGREN, J. Meso-level reasons for racism and xenophobia: some converging and diverging effects of radical right populism in France and Sweden. European Journal of Social Theory, v. 6, n. 1, p. 45-68, 2003. 
SAUER, W. National Socialism: Totalitarianism or Fascism?. American Historical Review, v. 73, n. 4, p. 404-424, 1967.

SCHAIN, M.; ZOLBERG, A.; HOSSAY, P. (Eds.). Shadows Over Europe: The Development and Impact of the Extreme Right in Western Europe. Houndsmill: Palgrave Macmillan, 2002.

STUDLAR, D.; MCALLISTER, I.; HAYES, B. Explaining the Gender Gap in Voting: A Cross-National Analysis. Social Science Quarterly, v. 79, n. 4, p. 779-798, 1998.

TINGSTEN, H. L. G. Political Behavior: Studies in Election Statistics. London: P. S. King, 1937.

VAN DER BRUG, W.; FENNEMA, M.; TILLIE, J. Anti-immigrant parties in Europe: Ideological or protest vote?. European Journal of Political Research, v. 37, n. 1, p. 77-102, 2000.

VAN DER BRUG, W.; FENNEMA, M. Protest or mainstream? How the European anti-immigrant parties developed into two separate groups by 1999. European Journal of Political Research, v. 42, n. 1, p. 55-76, 2003.

VEUGELERS, J. W. P. Social cleavage and the revival of far right parties: The case of France's National Front. Acta Sociologica, v. 40, n. 1, p. 31-49, 1997.

WILCOX, C. The causes and consequences of feminist consciousness among Western European women. Comparative Political Studies, v. 23, n. 4, p. 519-545, 1991.

Recebido para publicação em novembro de 2004.

Tradução e publicação autorizada pela autora.

Este texto é extraído do Capítulo 6 de Radical Right: Parties and Electoral Competition, livro que será publicado pela Cambridge University Press em 2005.

Tradução de Pedro Maia Soares. 